\title{
MicroRNA Detection through DNAzyme-Mediated Disintegration of Magnetic Nanoparticle Assemblies
}

Tian, Bo; Han, Yuanyuan; Wetterskog, Erik; Donolato, Marco; Hansen, Mikkel Fougt; Svedlindh, Peter; Strömberg, Mattias

\section{Published in:}

ACS Sensors

Link to article, DOI:

$10.1021 /$ acssensors. $8 \mathrm{~b} 00850$

Publication date:

2018

Document Version

Publisher's PDF, also known as Version of record

Link back to DTU Orbit

Citation (APA):

Tian, B., Han, Y., Wetterskog, E., Donolato, M., Hansen, M. F., Svedlindh, P., \& Strömberg, M. (2018).

MicroRNA Detection through DNAzyme-Mediated Disintegration of Magnetic Nanoparticle Assemblies. ACS Sensors, 3(9), 1884-1891. https://doi.org/10.1021/acssensors.8b00850

\section{General rights}

Copyright and moral rights for the publications made accessible in the public portal are retained by the authors and/or other copyright owners and it is a condition of accessing publications that users recognise and abide by the legal requirements associated with these rights.

- Users may download and print one copy of any publication from the public portal for the purpose of private study or research.

- You may not further distribute the material or use it for any profit-making activity or commercial gain

- You may freely distribute the URL identifying the publication in the public portal 


\title{
MicroRNA Detection through DNAzyme-Mediated Disintegration of Magnetic Nanoparticle Assemblies
}

\author{
Bo Tian, ${ }^{*}, \dagger, \ddagger$ Yuanyuan Han, ${ }^{\dagger}$ Erik Wetterskog, ${ }^{\dagger}$ Marco Donolato, ${ }^{\S}$ Mikkel Fougt Hansen, ${ }^{\ddagger}$ \\ Peter Svedlindh, ${ }^{\dagger}$ and Mattias Strömberg $*^{\dagger} \dagger$
}

${ }^{\dagger}$ Department of Engineering Sciences, Uppsala University, The Ångström Laboratory, Box 534, SE-751 21 Uppsala, Sweden

${ }^{\ddagger}$ Department of Micro- and Nanotechnology, Technical University of Denmark, DTU Nanotech, Building 345B, DK-2800 Kongens Lyngby, Denmark

${ }^{\S}$ BluSense Diagnostics, Fruebjergvej 3, DK-2100 Copenhagen, Denmark

\section{Supporting Information}

\begin{abstract}
DNA-assembled nanoparticle superstructures offer numerous bioresponsive properties that can be utilized for point-of-care diagnostics. Functional DNA sequences such as deoxyribozymes (DNAzymes) provide novel bioresponsive strategies and further extend the application of DNA-assembled nanoparticle superstructures. In this work, we describe a microRNA detection biosensor that combines magnetic nanoparticle (MNP) assemblies with DNAzyme-assisted target recycling. The DNA scaffolds of the MNP assemblies contain substrate sequences for DNAzyme and can form cleavage catalytic structures in the presence of target DNA or RNA sequences, leading to rupture of the scaffolds and disintegration

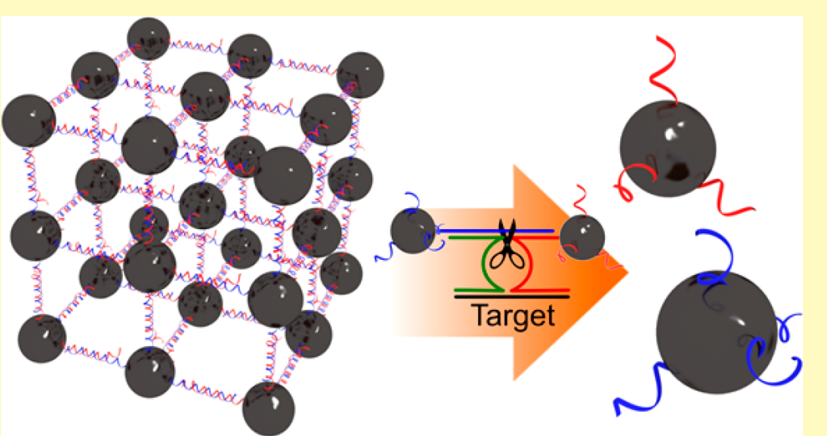
of the MNP assemblies. The target sequences are preserved during the cleavage reaction and release into the suspension to trigger the digestion of multiple DNA scaffolds. The high local concentration of substrate sequences in the MNP assemblies reduces the diffusion time for target recycling. The concentration of released MNPs, which is proportional to the concentration of the target, can be quantified by a $405 \mathrm{~nm}$ laser-based optomagnetic sensor. For the detection of let-7b in $10 \%$ serum, after $1 \mathrm{~h}$ of isothermal reaction at $50{ }^{\circ} \mathrm{C}$, we found a linear detection range between $10 \mathrm{pM}$ and $100 \mathrm{nM}$ with a limit of detection of 6 pM. For the quantification of DNA target in buffer solution, a limit of detection of $1.5 \mathrm{pM}$ was achieved. Compared to protein enzyme-based microRNA detection methods, the proposed DNAzyme-based biosensor has an increased stability, a reduced cost and a possibility to be used in living cells, all of which are valuable features for biosensing applications.
\end{abstract}

KEYWORDS: microRNA detection, DNAzyme, magnetic nanoparticles, DNA-assembled superstructures, optomagnetic bioassay

$\mathrm{D}$ riven by the requirements of point-of-care diagnostics, one of the recent themes in the field of nanotechnology is the assembly of nanosized building blocks into bioresponsive superstructures. DNA nanotechnology provides versatile tools for the controllable/programmable assembly of nanostructures. ${ }^{1-3}$ Since the first reports of programmable synthesis of nanomaterials in 1996, ,4 DNA molecules have been extensively studied as scaffolds for nanoparticle (NP) assemblies. $^{6-12}$ These DNA-based assemblies offer a number of distinct advantages owing to the unique properties of DNA, e.g., molecular net charge, controllable length, specific hybridization, and diversity of predictable reactions with enzymes. Nowadays, benefiting from the utilization of functional DNA sequences, e.g., deoxyribozymes (DNAzymes) and aptamers, applications of bioresponsive DNA-based NP assemblies have been further extended. ${ }^{13}$ DNAzymes are nuclease- or peroxidase-mimicking catalytic single-stranded DNA sequences, which are stable, low-cost, and easy to synthesize compared to protein enzymes. ${ }^{14-19}$ DNAzyme- based NP assemblies have been reported as biosensors for lead ions, ${ }^{20}$ indicators of multiple stimuli, ${ }^{21}$ and proofreading units in assembly processes. ${ }^{22}$ In particular, Zagorovsky and Chan reported a point-of-care DNA detection biosensor using multicomponent DNAzymes (MNAzymes) to switch the assembly states of AuNPs. ${ }^{23}$

Although the vast majority of previous studies on DNAbased NP assemblies have been carried out using AuNPs, magnetic nanoparticles (MNPs) are attractive candidates as building blocks in DNA-based assemblies due to their unique advantages. These include easy manipulation in magnetic field gradients, low background noise (biological tissues are diamagnetic), high signal stability, biocompatibility, and costefficiency. ${ }^{24}$ DNA-based MNP assemblies have been reported for drug delivery and biosensing applications. ${ }^{25-30}$ Recently,

Received: August 15, 2018

Accepted: September 6, 2018

Published: September 6, 2018 
Bakshi et al. reported an MNAzyme-based fluorescent biosensor for mRNA imaging, which utilized field-activated MNAzyme-MNPs to form assemblies in the presence of target mRNA in living cells. ${ }^{31}$ Herein, we conversely exploit MNAzymes for the disintegration of DNA-assembled MNP superstructures for the detection of microRNA, circumventing the need for applying magnetic fields. Since the substrate is already fixed with half of the DNAzyme cleavage catalytic core in the MNP assembly, the diffusion time for the initial cleavage catalytic action is shortened compared to other reported MNAzyme-based systems that need all four different sequences (i.e., target, substrate, and two components of the catalytic core) to diffuse to the correct position for hybridization. In the presence of target strands, the cleavage catalytic core of MNAzyme is stabilized, leading to a cleavage action that ruptures the DNA scaffold of the MNP assemblies, thereby releasing MNPs into the suspension. The target strands are preserved in the cleavage action and then released to trigger more cleaving reactions. This process, denoted DNAzymeassisted target recycling, ${ }^{32}$ disintegrates MNP assemblies and releases individual MNPs for the following detection.

MicroRNAs are 19- to 23-nucleotide long noncoding RNAs. Tissue-specific microRNAs can be used as biomarkers for tumor progression and metastasis. ${ }^{33-36}$ Traditional RNA detection methods, e.g., Northern blotting, oligonucleotide microarrays, and quantitative reverse transcription polymerase chain reaction, have limitations in microRNA analysis, mainly due to the short target sequences and the high sequence homology among microRNAs of the same family. ${ }^{37,38}$ By combining MNAzyme-MNP assemblies and DNAzymeassisted target recycling with a $405 \mathrm{~nm}$ laser-based optomagnetic sensor system, ${ }^{39}$ we demonstrate a homogeneous biosensor for microRNA detection. Compared to other microRNA detection systems using protein enzymes to amplify the signal, the proposed MNAzyme-based biosensor avoids the use of protein enzymes, which increases the stability and lowers the cost of the system. Therefore, the proposed biosensor is interesting for low-cost point-of-care cancer diagnostics. Moreover, without using protein enzymes, the MNAzyme-based strategy holds the possibility to be used in living cells for further biosensing applications. ${ }^{31,40,41}$ To the best of our knowledge, this is the first study reporting a strategy of MNAzyme-based disintegration of MNP assemblies.

\section{EXPERIMENTAL SECTION}

Chemicals and Sequences. Tris- $\mathrm{HCl}$ buffer solution (1 M, pH 8.0) was purchased from Thermo Fisher Scientific (Waltham, USA). $\mathrm{MgCl}_{2}$ and fetal bovine serum (FBS) were purchased from SigmaAldrich (St. Louis, USA). For DNAzyme-assisted target recycling, the working buffer was composed of $50 \mathrm{mM}$ Tris- $\mathrm{HCl}(\mathrm{pH} 8.0)$ and 50 $\mathrm{mM} \mathrm{MgCl} 2$. Streptavidin-coated $100 \mathrm{~nm}$ MNPs (product code 10-19102 , starch cross-linked multicore beads, where each bead consists of a cluster of single domain $\mathrm{Fe}_{3} \mathrm{O}_{4}$ nanocrystals) was purchased from Micromod Partikeltechnologie GmbH (Rostock, Germany). Pipette tips and storage tubes were RNase-free. DNA and RNA sequences were synthesized by Biomers (Ulm, Germany) and dissolved in 50 $\mathrm{mM}$ Tris- $\mathrm{HCl}(\mathrm{pH} \mathrm{8.0)}$ for storage. Table 1 shows all sequences of oligonucleotides used in this study.

DNA Conjugation of MNPs and Synthesis of MNP Assemblies. Streptavidin-coated $100 \mathrm{~nm}$ MNPs $(50 \mu \mathrm{L}$ of the stock solution, which contains $0.5 \mathrm{mg}$ of MNP and ca. $1 \mu \mathrm{g}$ of streptavidin according to the manufacturer) were washed twice and resuspended in $90 \mu \mathrm{L}$ working buffer before conjugation. Biotinylated substrate sequences $(10 \mu \mathrm{L}, 1 \mu \mathrm{M})$ were pipetted into the MNP
Table 1. Sequences of Oligonucleotides Used in This Study

\begin{tabular}{ll}
\multicolumn{1}{c}{ Name $^{a}$} & \multicolumn{1}{c}{ Sequence $\left(5^{\prime} \rightarrow 3^{\prime}\right)$} \\
let-7a & uga ggu agu agg uug uạu agu u \\
let-7b & uga ggu agu agg ung ugu ggu u \\
let-7c & uga ggu agu agg ung uạu ggu u \\
let-7d & aga ggu agu agg ung cau ạgu u \\
let-7e & uga ggu agg agg ung uạu agu u \\
D-let-7b & TGA GGT AGT AGG TTG TGT GGT T \\
DZa ${ }^{b}$ & AAC CAC ACA ACA CAA CGA GAG GAA ACC TT \\
DZb $^{c}$ & biotin-TTT TTT TTT TCA TTT GGT GCG AGG CTT GCC \\
& CAG GGA GGC TAG CTC TAC TAC CTC A \\
Substrate $^{d}$ & biotin-TTT TTT TTT TAA GGT TTC CTC guC CCT GGG \\
& CAA GCC TCG CAC CAA ATG CGA TTC CTA
\end{tabular}

${ }^{a}$ DNAs are written in uppercase letters while RNAs are written in lowercase letters. In let-7a, c, $d$ and e, the bases that differ from those in let- $7 \mathrm{~b}$ are bold and underlined. ${ }^{b}$ The target-binding region is bold and italicized. The substrate-binding region is bold. The cleavage catalytic region is underlined. ${ }^{c}$ The target-binding region is bold and italicized. The substrate-binding region is italicized. The cleavage catalytic region is underlined. ${ }^{d}$ The DZa-binding region is bold. The $\mathrm{DZb}$-binding region is italicized.

suspension for conjugation $\left(37^{\circ} \mathrm{C}, 30 \mathrm{~min}\right)$. Since the concentration of biotin groups was far below the concentration that can saturate the streptavidin on the surface of MNPs, it can be assumed that all biotinylated sequences were conjugated onto the MNP. Therefore, on average, there were 20 substrate or DZb sequences on each MNP. The DZb-MNPs were prepared in a similar way using biotinylated DZb sequences and streptavidin-coated MNPs. Substrate-MNPs and DZb-MNPs were mixed and the suspension was incubated at $77^{\circ} \mathrm{C}$ for $30 \mathrm{~min}$. The temperature of $77^{\circ} \mathrm{C}$ was chosen for the balance of minimum free energy, formation speed, and homogeneity of MNP assemblies. After the incubation, the mixture $(200 \mu \mathrm{L}, 5 \mathrm{mg} / \mathrm{mL}$ $\mathrm{MNP}$ ) was cooled down to room temperature and stored at $4{ }^{\circ} \mathrm{C}$ for $48 \mathrm{~h}$ to form MNP assemblies before use.

MicroRNA Detection Using DNAzyme-Assisted Target Recycling. The reaction suspension $(100 \mu \mathrm{L})$ contained $5 \mu \mathrm{L}$ of MNP assemblies, $5 \mu \mathrm{L}$ of DZa $(100 \mathrm{nM})$, and $90 \mu \mathrm{L}$ of the sample (containing target sequences). After addition of MNP assemblies and $\mathrm{DZa}$ into the sample, the suspension was incubated at $50{ }^{\circ} \mathrm{C}$ to perform DNAzyme-assisted target recycling. Thereafter, the suspension was pipetted to a UV-transparent cuvette (REF 67.758.001, Nümbrecht, Germany) for optomagnetic measurement of the released MNPs. For each sample measured in the experiments for system optimization, target quantification, and specificity test, three replicate measurements were performed, and the standard deviations were plotted as error bars.

Optomagnetic Measurement. An alternating current (AC) magnetic excitation field $B(t)=B_{0} \sin (2 \pi f t)$ with $B_{0}=2.6 \mathrm{mT}$ was applied to actuate the rotation of MNPs suspended in the cuvette. A $405 \mathrm{~nm}$ laser beam was applied perpendicular to the magnetic field to measure the motion of the MNPs. The diameter and the optical path of the laser beam were $2 \mathrm{~mm}$ and $10 \mathrm{~mm}$, respectively. During each measurement, the real part of the second harmonic component of the transmitted light intensity, $V_{2}^{\prime} \propto \sin (4 \pi f t)$, was recorded at 13 logarithmically spaced frequencies $(55-1000 \mathrm{~Hz})$ with a total data acquisition time of $120 \mathrm{~s}$. The zeroth harmonic (DC) signal $V_{0}$ was recorded simultaneously. To compensate for possible variations of the intensity of light, all results are presented as normalized values $V_{2}^{\prime} / V_{0}$. A detailed description of the optomagnetic sensor system and measurement principle as well as the underlying theory is given in Supporting Information, section S1.

SEM and DLS Characterization. The nanostructures of the dispersed multicore MNPs (substrate sequence-conjugated MNPs) and the MNP assemblies were characterized by scanning electron microscopy (SEM, Zeiss-1550). The secondary electron images were obtained using an in-lens detector at $10 \mathrm{kV}$ accelerating voltage. Samples were dispersed on a $\mathrm{SiO}_{2} / \mathrm{Si}$ substrate and blown dried with 


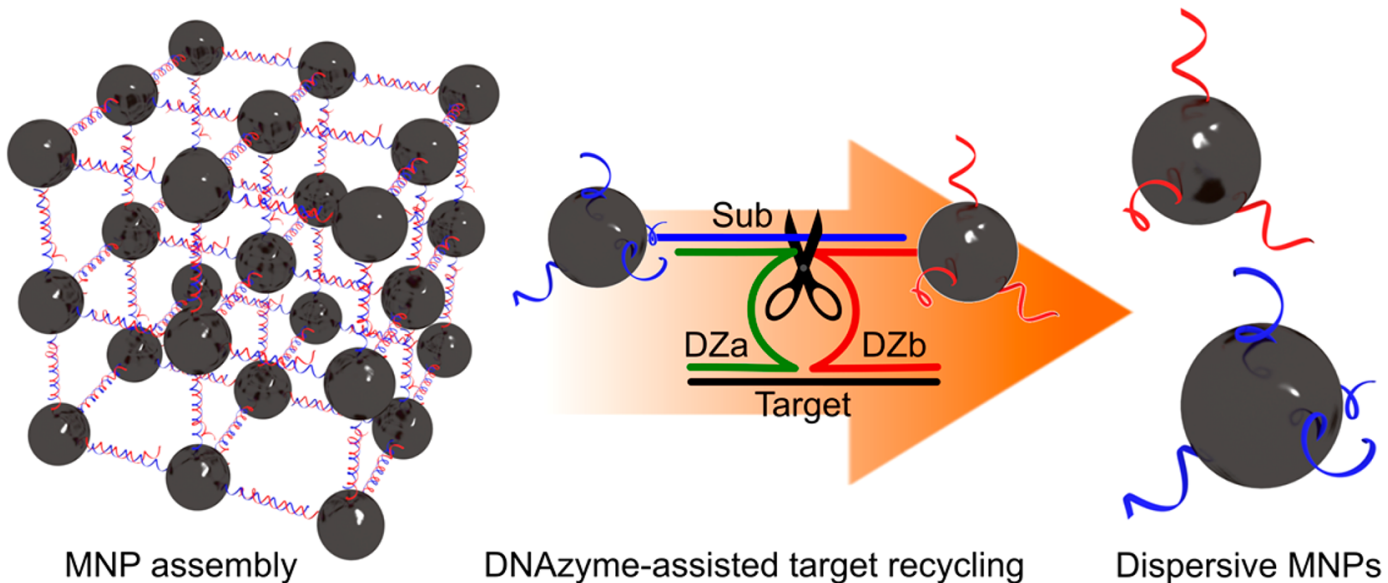

Figure 1. Schematic illustration of the DNAzyme-mediated disintegration of MNP assemblies. Together with DZa, a target sequence forms a cleavage catalytic structure with the DNA scaffold. The active catalytic structure cleaves the substrate sequence and leads to the disintegration of the MNP assemblies. Target sequence and DZa are preserved in the reaction and are able to trigger the digestion of multiple DNA scaffolds.
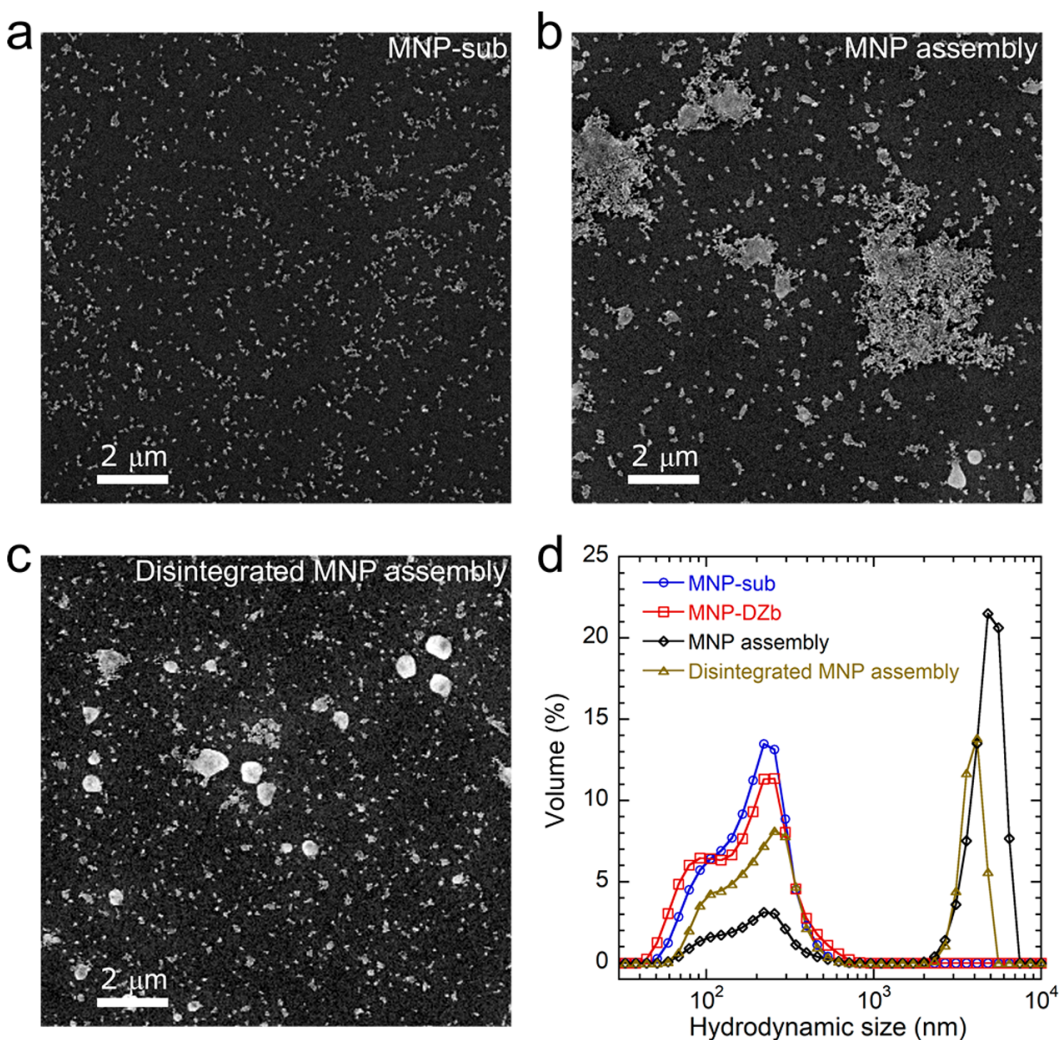

Figure 2. Representative SEM micrographs of (a) dispersive sequence-conjugated MNPs, (b) MNP assemblies, and (c) disintegrated MNP assemblies. (d) DLS measurement results showing the size distribution (weighted by volume) of dispersive sequence-conjugated MNPs, MNP assemblies, and disintegrated MNP assemblies.

$\mathrm{N}_{2}$ to avoid drying induced aggregation. The hydrodynamic sizes of MNPs and MNP assemblies in buffer solution were characterized by dynamic light scattering (DLS) measurements (Zetasizer Nano ZSP) using a $\mathrm{He}-\mathrm{Ne} 633 \mathrm{~nm}$ laser.

\section{RESULTS AND DISCUSSION}

Biosensing Principle. The detection principle of the proposed biosensor is based on the DNAzyme-mediated disintegration of MNP assemblies. In the strategy of multicomponent DNAzyme (MNAzyme), the cleavage catalytic core of the DNAzyme has been split into two components, $\mathrm{DZa}$ and DZb. Except for the catalytic core sequences, both
$\mathrm{DZa}$ and $\mathrm{DZb}$ contain a target-binding region and a substratebinding region (Table 1). MNP assemblies are formed based on the hybridization between the substrate sequence (blue sequences in Figure 1) and DZb (red sequences in Figure 1) conjugated on different MNPs. For target DNA or RNA detection, target sequences (the black sequence in Figure 1) are added together with $\mathrm{DZa}$ (the green sequence in Figure 1), thereby forming intact MNAzyme structures on DNA scaffolds with cleavage catalytic cores. Then the cleavage catalytic action ruptures the substrate sequences, resulting in the disintegration of the MNP assemblies. The target sequence and DZa, which 

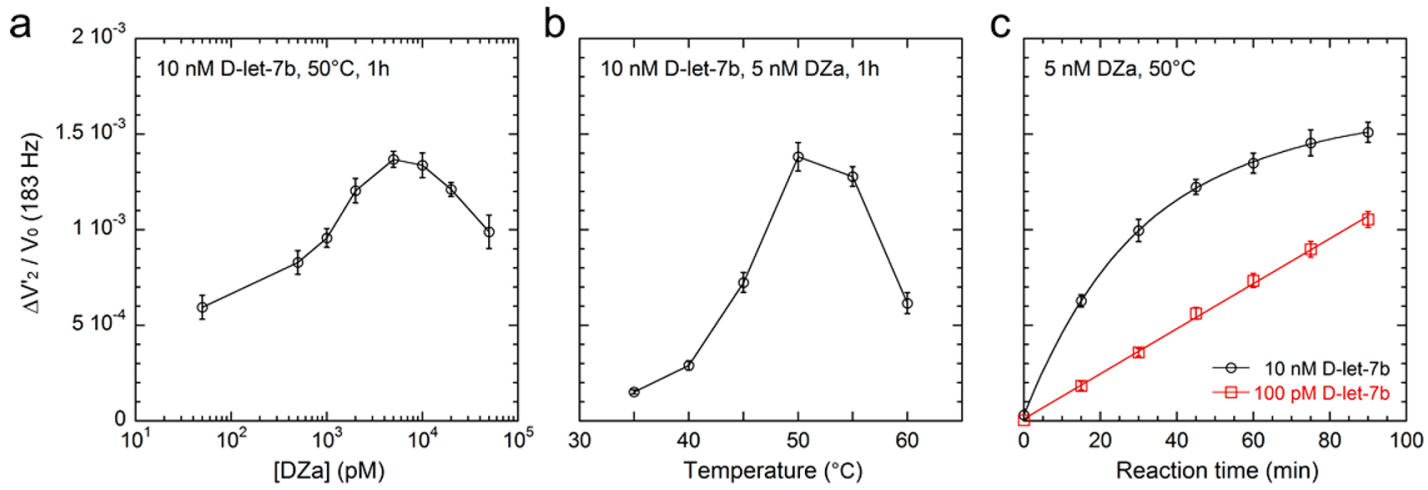

Figure 3. Effects of (a) concentration of $\mathrm{DZa}$, (b) reaction temperature, and (c) reaction time on the optomagnetic peak amplitude, $\Delta V_{2}^{\prime} / V_{0}(183$ $\mathrm{Hz}$ ). The DNA target, D-let-7b, was used for the optimization. Error bars indicate the standard deviation based on three independent measurements.

are preserved during the cleavage reaction, are released into the suspension to trigger the digestion of multiple DNA scaffolds, leading to the continued release of MNPs (Figure 1). Released MNPs are quantified by the optomagnetic setup.

The real part of the normalized optomagnetic spectra, $V_{2}^{\prime} /$ $V_{0}$, for free MNPs displays a peak at ca. $180 \mathrm{~Hz}$, which is related but not precisely equal to the Brownian relaxation frequency of the $100 \mathrm{~nm} \mathrm{MNPs}{ }^{42}$ In this study, the optomagnetic signal increase $\left[\Delta V_{2}^{\prime} / V_{0}=\left(V_{2}^{\prime} / V_{0}\right)_{\text {sample }}-\right.$ $\left.\left(V_{2}^{\prime} / V_{0}\right)_{\text {blank }}\right]$ at the peak position $(183 \mathrm{~Hz})$ is used for the target quantification, where $\left(V_{2}^{\prime} / V_{0}\right)_{\text {blank }}$ represents the average peak amplitude of blank control samples. The underlying theory and details of the sensor can be found in Supporting Information, section $\mathrm{S} 1$ as well as in several previous publications. $^{43-45}$

Characterization of the DNA-Assembled MNP Assemblies. DNA-assembled MNP superstructures were prepared by simply mixing substrate sequence-conjugated MNPs and DZbconjugated MNPs. The process of DNA-mediated MNP assembling is strongly influenced by the number of substrate or $\mathrm{DZb}$ sequences conjugated on each MNP. Evaluation of different DNA:MNP ratios, ranging from 5:1 to $120: 1$, is given in Supporting Information, section S2. It was concluded that a DNA:MNP ratio of 20:1 was optimal to use for the proposed biosensing design. Evidence for the formation of MNP assemblies was provided by SEM and DLS measurements. SEM micrographs of substrate sequence-conjugated MNPs (MNP-sub) and MNP assemblies are shown in Figure 2a and $b$, respectively. As can be seen in Figure $2 b$, most of the MNPs are incorporated in micron-sized assemblies. However, since each $100 \mathrm{~nm} \mathrm{MNP}$ is an irregular cluster of small single domain particles, the MNP assemblies appear in the SEM micrographs as large clusters of small single domain particles (Figure S4), and therefore the arrangement of $100 \mathrm{~nm}$ MNPs in the assemblies cannot be resolved. DLS measurements also demonstrated the assembly of substrate sequence-conjugated MNPs and DZb-conjugated MNPs (cf. Figure 2d).

As can be observed in Figure $2 b$, the as-prepared MNP assemblies are not homogeneous, which may be caused by (1) the ratio of the two kinds of MNPs is not $1: 1$; (2) the shape of MNPs used in this work is irregular; (3) MNP surface coating and DNA conjugation are not homogeneous; and (4) equilibrium of the MNP assembling reaction is not reached. The homogeneity of the MNP assemblies is related to the surface area of the assemblies, thus influencing the DNAzyme reaction speed. However, since in this study $[\mathrm{DZa}]$ is much lower than the local concentration of DNA scaffold (which is within the $\mu \mathrm{M}$ range, as estimated by the DNA binding ratio and DLS results) in the MNP assemblies, the DNAzyme reaction speed was limited by the lower one between [DZa] and [target] but not by the surface area of assemblies. Additionally, due to the large hydrodynamic size, MNP assemblies have no optomagnetic signal contribution in the detection window of 55-1000 Hz. Therefore, we conclude that the inhomogeneity of the MNP assemblies has limited influence on the sensing reproducibility.

Feasibility of DNAzyme-Mediated Disintegration of MNP Assemblies. To demonstrate the working principle of our design, the as-prepared MNP assemblies were reacted with $10 \mathrm{nM}$ of D-let-7b and $5 \mathrm{nM}$ of DZa at $50{ }^{\circ} \mathrm{C}$ for $2 \mathrm{~h}$, followed by SEM and DLS measurements. To avoid MNP aggregation induced by magnetic separation, the magnetic suspension containing disintegrated MNP assemblies was directly diluted by pure water for SEM measurement. As shown by the SEM micrograph (Figure 2c), large MNP assemblies disappeared after the DNAzyme-assisted target recycling reaction, which demonstrates the feasibility of the biosensing design. However, some small MNP assemblies can still be observed after DNAzyme-mediated disintegration, implying that the reaction was not totally finished. Additionally, DLS measurement results (yellow triangles in Figure $2 \mathrm{~d}$ ) demonstrated the size decrease of MNP assemblies as well as the release of individual MNPs.

Assay Optimization Using D-let-7b. The performance of the DNAzyme-mediated disintegration of MNP assemblies is influenced by several experimental conditions, e.g., [DZa] (the working concentration of $\mathrm{DZa}$ ), the reaction temperature and the reaction time. To optimize the experimental conditions, Dlet-7b was used as the target sequence due to the instability of microRNA molecules. First, we evaluated the effect of [DZa] on the proposed biosensing strategy. After $1 \mathrm{~h}$ of DNAzymeassisted target recycling at $50{ }^{\circ} \mathrm{C}$ using $10 \mathrm{nM}$ of D-let-7b and different $[\mathrm{DZa}]$, a maximum optomagnetic signal was observed at $[\mathrm{DZa}]=5 \mathrm{nM}$, which can be seen in Figure 3a. At very low DZa concentrations $([\mathrm{DZa}] \ll[$ target $])$, the number as well as the formation speed of catalytic MNAzyme structures were limited by $[\mathrm{DZa}]$; whereas at very high $\mathrm{DZ}$ a concentrations $([\mathrm{DZa}]>10 \mathrm{nM})$, catalytic MNAzyme structures can be formed without being stabilized by the target sequences, leading to an increase of the nonspecific signal and thus a decrease of $\Delta V_{2}^{\prime} / V_{0}(183 \mathrm{~Hz})$. Second, the influence of reaction temperature was investigated. The optimized reaction 
temperature for the proposed strategy was around $50{ }^{\circ} \mathrm{C}$ (Figure 3b). At temperatures higher than $50{ }^{\circ} \mathrm{C}$, the signal decreased dramatically due to the denaturation of MNAzyme structures. We have also made a rough evaluation of the influence of $[\mathrm{DZa}]$ and the reaction temperature using the RNA target, resulting in similar optimal conditions (data not shown). Finally, in the time-resolved measurement, the $\Delta V_{2}^{\prime}$ / $V_{0}(183 \mathrm{~Hz})$ signal increased as a function of reaction time (Figure 3c). For a high target concentration (10 nM of D-let$7 \mathrm{~b}$, black circles in Figure 3c), the signal increased fast during the first $30 \mathrm{~min}$ but slowed down significantly as the experiment progressed. For a low target concentration (100 pM of D-let-7b, red squares in Figure $3 \mathrm{c}), \Delta V_{2}^{\prime} / V_{0}(183 \mathrm{~Hz})$ increases linearly with reaction time in the interval 0-90 min. Because of the linear increase (with reaction time) of the signal due to DNAzyme-assisted target recycling, the sensitivity of the proposed strategy can be improved by extending the reaction time. Due to the instability of embedded RNA in the DNA scaffold, MNP assemblies were disintegrated nonspecifically at $50{ }^{\circ} \mathrm{C}$ (black circles in Figure S5). Moreover, DZa molecules could form catalytic MNAzyme structures with the DNA scaffold without being stabilized by the target sequences, which contributed to the nonspecific disintegration of MNP assemblies as well (red squares in Figure S5). These nonspecific background signals were eliminated in this study since we considered the signal increase $\left[\Delta V_{2}^{\prime} / V_{0}=\left(V_{2}^{\prime} /\right.\right.$ $\left.\left.V_{0}\right)_{\text {sample }}-\left(V_{2}^{\prime} / V_{0}\right)_{\text {blank }}\right]$ instead of the signal $\left[\left(V_{2}^{\prime} / V_{0}\right)_{\text {sample }}\right]$ itself. Considering the instability of RNA sequences (especially when RNase inhibitors are not used), we chose $1 \mathrm{~h}$ as the reaction time for the following experiments.

The theoretical basis of assembling and disintegration of DNA structures can be provided either by analyzing the melting temperature $\left(T_{\mathrm{m}}\right)$ or the minimum free energy (MFE). For short dsDNA sequences, $T_{\mathrm{m}}$ of substrate-DZb (DNA scaffold) is approximately $82-84{ }^{\circ} \mathrm{C}$, which means that the MNP assembly should be stable at $50{ }^{\circ} \mathrm{C} . T_{\mathrm{m}}$ of DZa-substrate, DZa-target, and DZb-target are all approximately $32{ }^{\circ} \mathrm{C}$, which means that $\mathrm{DZa}$ and the target sequence can theoretically be released from the MNAzyme structure at $50{ }^{\circ} \mathrm{C}$ after the hybridization reaction, carrying out next recycling. The MFE secondary structure and thermal stability of MNAzyme are analyzed by NUPACK (http://www.nupack.org/). Sequences of catalytic core are replaced by poly $\mathrm{T}$ to avoid secondary structures formed in the catalytic core. At the condition of 50 ${ }^{\circ} \mathrm{C}$, the MFE of substrate-DZb (DNA scaffold) and substrateDZb-Target-DZa (MNAzyme) are $-33.29 \mathrm{kcal} / \mathrm{mol}$ and $-58.19 \mathrm{kcal} / \mathrm{mol}$, respectively, indicating the stability of the MNAzyme structure. Therefore, it can be concluded that the target sequences can hybridize with $\mathrm{DZ}$ a and $\mathrm{DZb}$ to form the MNAzyme structure at $50{ }^{\circ} \mathrm{C}$. Additionally, the MFE of DZasubstrate- $\mathrm{DZb}$ is $-45.10 \mathrm{kcal} / \mathrm{mol}$, implying the stabilization effect of target sequences. The MFE secondary structures estimated by NUPACK are shown in Figure S6.

Quantitative detection of D-let-7b was investigated under optimal experimental conditions $(5 \mathrm{nM}$ of DZa, $1 \mathrm{~h}$ incubation at $\left.50{ }^{\circ} \mathrm{C}\right)$. Target DNA sequences were serially diluted by working buffer to concentrations ranging from $0.1 \mathrm{pM}$ to 0.1 $\mu \mathrm{M}$ and reacted with MNP assemblies as well as DZa. With increasing D-let-7b concentration, the peak amplitude of the $V_{2}^{\prime} / V_{0}$ spectra shows a monotonous increase (Figure 4a). From the dose-response curve (Figure $4 \mathrm{~b}$ ) we observe that the increase of peak amplitude measured at $183 \mathrm{~Hz}, V_{2}^{\prime} / V_{0}(183$ $\mathrm{Hz}$ ), has a linear correlation with the (logarithmic) target
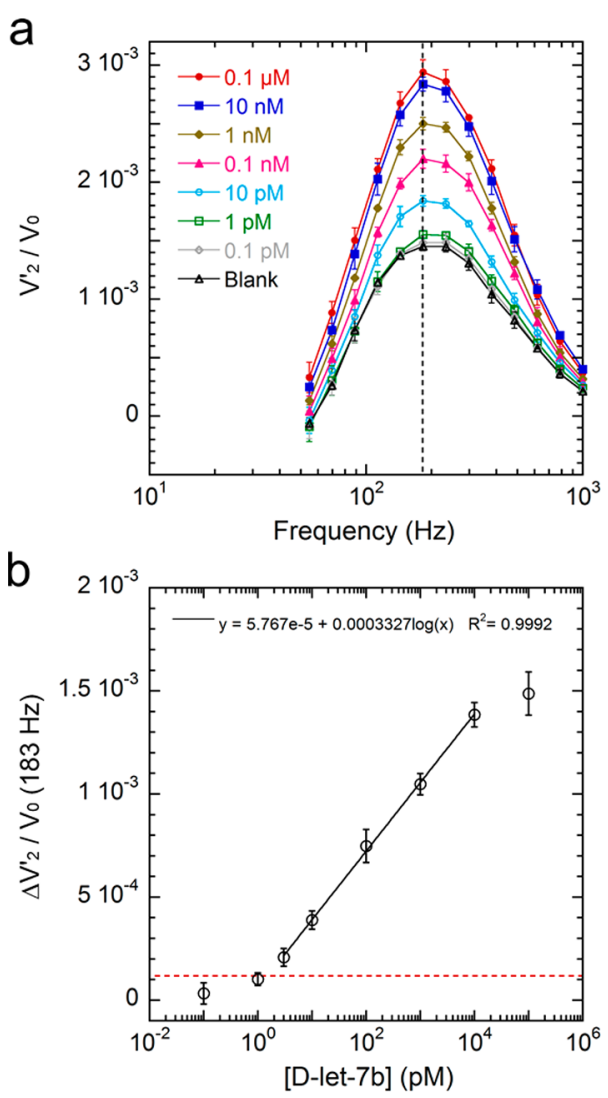

Figure 4. Optomagnetic spectra (a) and dose-response curve (b) for DNA target quantification in buffer solutions using the strategy of DNAzyme-mediated disintegration of MNP assemblies. The black dashed line in (a) indicates the peak frequency of $183 \mathrm{~Hz}$. The red dashed line in (b) indicates the cutoff value obtained based on the $3 \sigma$ criterion. Error bars indicate the standard deviation based on three independent measurements.

concentration between $3 \mathrm{pM}$ and $10 \mathrm{nM}$. The cutoff value, indicated as the red dashed line in Figure 4b, was calculated as three standard deviations of the peak amplitude obtained from blank control samples. A limit of detection (LOD) of $1.5 \mathrm{pM}$ was obtained based on the $3 \sigma$ criterion. As a comparison, LODs reported by other MNAzyme-based DNA biosensors (based on 10-23 DNAzyme) are $5 \mathrm{pM}^{46} 11 \mathrm{pM}^{47} 50 \mathrm{pM}^{23}$ and $6 \mathrm{nM}^{48}$ It has been reported that the catalytic efficiency of the 10-23 DNAzyme can only be improved by facilitated substrate delivery. ${ }^{49}$ Therefore, we ascribe the high sensitivity to the utilization of MNP assemblies, which offer a high local concentration of fixed substrate-DZb structures, thus reducing the diffusion time needed for the formation of active MNPzyme structures. Bakshi et al. utilized field-activated aggregation of MNAzyme-MNPs for obtaining high local concentrations of reacting sequences. ${ }^{31,50}$ However, the sensitivity of this design was not specified in their publications. Except for the sensitivity, the utilization of optomagnetic readout offers several other advantages compared with previously reported MNAzyme-based biosensors which all employed colorimetric or fluorescent readouts. First, colorimetric or fluorescent dyes served only as detection labels, while MNPs used in the proposed biosensing design served as labels, carriers and building blocks, and hold the potential for magnetic field-manipulated enrichment, separation, and purification. Second, biological tissues always contain back- 
ground colorimetric and/or fluorescent noise, which influences the results and limits the sensitivity of colorimetric or fluorescent methods. Finally, magnetic labels have much higher signal stability compared to colorimetric or fluorescent dyes.

Detection of let-7b in Serum. For the proposed biosensor, it is not relevant to perform cell lysate measurements since the LOD is at the picomolar level, close to the level of the total microRNA concentration in lysates of, e.g., HeLa cells. Apart from tissues, microRNAs also exist in body fluids such as serum. ${ }^{51,52}$ To demonstrate the robustness of the proposed biosensor against matrix effects, let-7b microRNA sequences were quantified in working buffer containing fetal bovine serum (FBS). The target microRNA was spiked into $10 \%$ FBS to a series of concentrations ranging from $0.1 \mathrm{pM}$ to $0.1 \mu \mathrm{M}$, and were measured using the proposed method under optimal experimental conditions. The dose-response curve for target microRNA in 10\% FBS is shown in Figure 5a. A linear
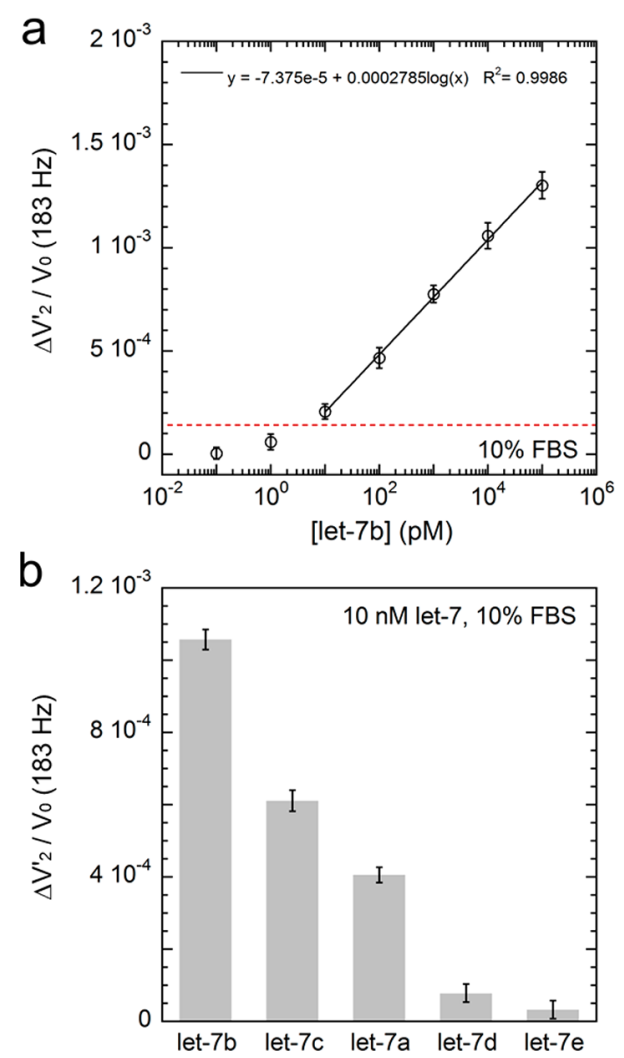

Figure 5. MicroRNA detection in 10\% FBS. (a) Dose-response curve for let-7b quantification using the proposed biosensing strategy. The red dashed line indicates the cutoff value based on the $3 \sigma$ criterion. (b) Specificity test using $10 \mathrm{nM}$ of different let-7 microRNAs. Error bars indicate the standard deviation based on three independent measurements.

detection range from $10 \mathrm{pM}$ to $0.1 \mu \mathrm{M}$ is observed with an LOD of $6 \mathrm{pM}$. Compared to the DNA quantification in buffer solutions, the reaction speed of RNA detection in 10\% FBS is slightly lower (cf. equations of the linear parts in Figures $4 \mathrm{~b}$ and 5a), which may be caused by the matrix effects as well as the lower stability of DNA:RNA duplexes compared to DNA:DNA duplexes. ${ }^{48,53}$

Specificity Test. One of the most challenging parts in microRNA biosensing is the discrimination between micro-
RNAs of the same family. A specificity test was performed for the detection of $10 \mathrm{nM}$ of different let-7 microRNAs (Figure $5 b$ ) in $10 \%$ FBS. As can be seen in Table 1, let- 7 microRNAs have a high sequence homology, which means nontarget let-7 microRNAs may be capable of forming active MNAzymes with DZa and DNA scaffolds, leading to nonspecific signals. For the detection of $10 \mathrm{nM}$ of let-7c, which has a single-nucleotide mismatch with the target-binding region of the MNAzyme, a high nonspecific signal was observed equal in magnitude to the signal of $288 \mathrm{pM}$ of let-7b (calculated by using the equation in Figure 5a). The second highest nonspecific signal was observed in the detection of $10 \mathrm{nM}$ of let-7a (double-nucleotide mismatch), which was found to be equal to the signal of $53 \mathrm{pM}$ of let-7b. Nonspecific signals from $10 \mathrm{nM}$ of let-7d and let-7e were negligible (below the cutoff value). Results of the specificity test demonstrate that the proposed biosensor is capable of discriminating nontarget RNA sequences from those containing even single-nucleotide mismatches, in agreement with a previous study ${ }^{40}$ on miR-21 detection.

\section{CONCLUSIONS}

In summary, a strategy of DNAzyme-mediated disintegration of MNP assemblies was demonstrated for the detection of short (ca. $20 \mathrm{nt}$ ) single-stranded DNA or RNA targets. DNAzyme-assisted target recycling was utilized to rupture the DNA scaffold of the MNP assemblies. The proposed biosensor achieved an LOD of $1.5 \mathrm{pM}$ target DNA in buffer, and an LOD of $6 \mathrm{pM}$ target microRNA in 10\% FBS. The high local concentration of substrate sequences in the MNP assemblies reduces the diffusion time for target recycling, thus providing a high sensitivity. In addition, circumventing the use of protein enzymes, the proposed biosensor shows increased stability and a reduced cost as compared to protein enzyme-based detection systems, which strengthens its potential for further application in point-of-care diagnostics.

\section{ASSOCIATED CONTENT}

\section{Supporting Information}

The Supporting Information is available free of charge on the ACS Publications website at DOI: 10.1021/acssensors. 8 b00850.

Optomagnetic system description and optomagnetic measurement principle; evaluation of MNP assemblies employing different DNA:MNP ratios; observation of details of MNP assemblies using SEM; time-resolved nonspecific disintegration of MNP assemblies; MFE secondary structures estimated by NUPACK (PDF)

\section{AUTHOR INFORMATION}

\section{Corresponding Authors}

*E-mail: botia@nanotech.dtu.dk.

*E-mail: mattias.stromberg@angstrom.uu.se.

ORCID

Bo Tian: 0000-0002-5249-4415

Erik Wetterskog: 0000-0002-6681-4803

Mattias Strömberg: 0000-0003-0648-3130

Notes

The authors declare no competing financial interest. 


\section{ACKNOWLEDGMENTS}

This work was financially supported by Swedish Research Council Formas (project no. 221-2012-444 and 2011-1692) and EU FP7 grant no. 604448-NanoMag.

\section{REFERENCES}

(1) Seeman, N. C. DNA in a material world. Nature 2003, 421, 427-431.

(2) Tan, S. J.; Campolongo, M. J.; Luo, D.; Cheng, W. L. Building plasmonic nanostructures with DNA. Nat. Nanotechnol. 2011, 6, 268276.

(3) Li, F. Y.; Lu, J. X.; Kong, X. Q.; Hyeon, T.; Ling, D. S. Dynamic Nanoparticle Assemblies for Biomedical Applications. Adv. Mater. 2017, 29, 1605897.

(4) Mirkin, C. A.; Letsinger, R. L.; Mucic, R. C.; Storhoff, J. J. A DNA-based method for rationally assembling nanoparticles into macroscopic materials. Nature 1996, 382, 607-609.

(5) Alivisatos, A. P.; Johnsson, K. P.; Peng, X. G.; Wilson, T. E.; Loweth, C. J.; Bruchez, M. P.; Schultz, P. G. Organization of 'nanocrystal molecules' using DNA. Nature 1996, 382, 609-611.

(6) Nykypanchuk, D.; Maye, M. M.; van der Lelie, D.; Gang, O. DNA-guided crystallization of colloidal nanoparticles. Nature 2008, 451, 549-552.

(7) Park, S. Y.; Lytton-Jean, A. K. R.; Lee, B.; Weigand, S.; Schatz, G. C.; Mirkin, C. A. DNA-programmable nanoparticle crystallization. Nature 2008, 451, 553-556.

(8) Macfarlane, R. J.; Lee, B.; Jones, M. R.; Harris, N.; Schatz, G. C.; Mirkin, C. A. Nanoparticle Superlattice Engineering with DNA. Science 2011, 334, 204-208.

(9) Kuzyk, A.; Schreiber, R.; Fan, Z. Y.; Pardatscher, G.; Roller, E. M.; Hogele, A.; Simmel, F. C.; Govorov, A. O.; Liedl, T. DNA-based self-assembly of chiral plasmonic nanostructures with tailored optical response. Nature 2012, 483, 311-314.

(10) Zhang, Y. G.; Lu, F.; Yager, K. G.; van der Lelie, D.; Gang, O. A general strategy for the DNA-mediated self-assembly of functional nanoparticles into heterogeneous systems. Nat. Nanotechnol. 2013, 8, $865-872$.

(11) Chou, L. Y. T.; Zagorovsky, K.; Chan, W. C. W. DNA assembly of nanoparticle superstructures for controlled biological delivery and elimination. Nat. Nanotechnol. 2014, 9, 148-155.

(12) Yu, Q. Y.; Zhang, X. N.; Hu, Y.; Zhang, Z. H.; Wang, R. Dynamic Properties of DNA-Programmable Nanoparticle Crystallization. ACS Nano 2016, 10, 7485-7492.

(13) Tan, L. H.; Xing, H.; Lu, Y. DNA as a Powerful Tool for Morphology Control, Spatial Positioning, and Dynamic Assembly of Nanoparticles. Acc. Chem. Res. 2014, 47, 1881-1890.

(14) Hollenstein, M.; Hipolito, C.; Lam, C.; Dietrich, D.; Perrin, D. M. A highly selective DNAzyme sensor for mercuric ions. Angew. Chem., Int. Ed. 2008, 47, 4346-4350.

(15) Ali, M. M.; Aguirre, S. D.; Lazim, H.; Li, Y. F. Fluorogenic DNAzyme Probes as Bacterial Indicators. Angew. Chem., Int. Ed. 2011, 50, 3751-3754.

(16) Wang, F.; Elbaz, J.; Orbach, R.; Magen, N.; Willner, I. Amplified Analysis of DNA by the Autonomous Assembly of Polymers Consisting of DNAzyme Wires. J. Am. Chem. Soc. 2011, 133, 17149-17151.

(17) Wang, F. A.; Elbaz, J.; Teller, C.; Willner, I. Amplified Detection of DNA through an Autocatalytic and Catabolic DNAzyme-Mediated Process. Angew. Chem., Int. Ed. 2011, 50, 295-299.

(18) Liu, X. Q.; Niazov-Elkan, A.; Wang, F. A.; Willner, I. Switching Photonic and Electrochemical Functions of a DNAzyme by DNA Machines. Nano Lett. 2013, 13, 219-225.

(19) Wu, P. W.; Hwang, K. V.; Lan, T.; Lu, Y. A DNAzyme-Gold Nanoparticle Probe for Uranyl Ion in Living Cells. J. Am. Chem. Soc. 2013, 135, 5254-5257.
(20) Liu, J. W.; Lu, Y. Accelerated color change of gold nanoparticles assembled by DNAzymes for simple and fast colorimetric $\mathrm{Pb} 2+$ detection. J. Am. Chem. Soc. 2004, 126, 12298-12305.

(21) Lee, J. H.; Wang, Z. D.; Liu, J. W.; Lu, Y. Highly Sensitive and Selective Colorimetric Sensors for Uranyl (UO22+): Development and Comparison of Labeled and Label-Free DNAzyme-Gold Nanoparticle Systems. J. Am. Chem. Soc. 2008, 130, 14217-14226.

(22) Liu, J. W.; Wernette, D. P.; Lu, Y. Proofreading and error removal in a nanomaterial assembly. Angew. Chem., Int. Ed. 2005, 44, $7290-7293$.

(23) Zagorovsky, K.; Chan, W. C. W. A Plasmonic DNAzyme Strategy for Point-of-Care Genetic Detection of Infectious Pathogens. Angew. Chem., Int. Ed. 2013, 52, 3168-3171.

(24) Lee, H.; Shin, T. H.; Cheon, J.; Weissleder, R. Recent Developments in Magnetic Diagnostic Systems. Chem. Rev. 2015, 115, 10690-10724.

(25) Perez, J. M.; O’Loughin, T.; Simeone, F. J.; Weissleder, R.; Josephson, L. DNA-based magnetic nanoparticle assembly acts as a magnetic relaxation nanoswitch allowing screening of DNA-cleaving agents. J. Am. Chem. Soc. 2002, 124, 2856-2857.

(26) Ruiz-Hernandez, E.; Baeza, A.; Vallet-Regi, M. Smart Drug Delivery through DNA/Magnetic Nanoparticle Gates. ACS Nano 2011, 5, 1259-1266.

(27) Leslie, D. C.; Li, J. Y.; Strachan, B. C.; Begley, M. R.; Finkler, D.; Bazydlo, L. A. L.; Barker, N. S.; Haverstick, D. M.; Utz, M.; Landers, J. P. New Detection Modality for Label-Free Quantification of DNA in Biological Samples via Superparamagnetic Bead Aggregation. J. Am. Chem. Soc. 2012, 134, 5689-5696.

(28) Ma, W.; Yin, H. H.; Xu, L. G.; Wang, L. B.; Kuang, H.; Xu, C. L. A PCR based magnetic assembled sensor for ultrasensitive DNA detection. Chem. Commun. 2013, 49, 5369-5371.

(29) Liong, M.; Im, H.; Majmudar, M. D.; Aguirre, A. D.; Sebas, M.; Lee, H.; Weissleder, R. Magnetic Ligation Method for Quantitative Detection of MicroRNAs. Adv. Healthcare Mater. 2014, 3, 10151019.

(30) Tian, B.; Qiu, Z.; Ma, J.; Donolato, M.; Hansen, M. F.; Svedlindh, P.; Strömberg, M. On-Particle Rolling Circle Amplification-Based Core-Satellite Magnetic Superstructures for MicroRNA Detection. ACS Appl. Mater. Interfaces 2018, 10, 2957-2964.

(31) Bakshi, S. F.; Guz, N.; Zakharchenko, A.; Deng, H.; Tumanov, A. V.; Woodworth, C. D.; Minko, S.; Kolpashchikov, D. M.; Katz, E. Magnetic Field-Activated Sensing of mRNA in Living Cells. J. Am. Chem. Soc. 2017, 139, 12117-12120.

(32) Kolpashchikov, D. M. A binary deoxyribozyme for nucleic acid analysis. ChemBioChem 2007, 8, 2039-2042.

(33) Lu, J.; Getz, G.; Miska, E. A.; Alvarez-Saavedra, E.; Lamb, J.; Peck, D.; Sweet-Cordero, A.; Ebet, B. L.; Mak, R. H.; Ferrando, A. A.; Downing, J. R.; Jacks, T.; Horvitz, H. R.; Golub, T. R. MicroRNA expression profiles classify human cancers. Nature 2005, 435, 834838

(34) Esquela-Kerscher, A.; Slack, F. J. Oncomirs - microRNAs with a role in cancer. Nat. Rev. Cancer 2006, 6, 259-269.

(35) Calin, G. A.; Croce, C. M. MicroRNA signatures in human cancers. Nat. Rev. Cancer 2006, 6, 857-866.

(36) Inui, M.; Martello, G.; Piccolo, S. MicroRNA control of signal transduction. Nat. Rev. Mol. Cell Biol. 2010, 11, 252-263.

(37) Baker, M. MicroRNA profiling: separating signal from noise. Nat. Methods 2010, 7, 687-692.

(38) Shen, Y. T.; Tian, F.; Chen, Z. Z.; Li, R.; Ge, Q. Y.; Lu, Z. H. Amplification-based method for microRNA detection. Biosens. Bioelectron. 2015, 71, 322-331.

(39) Donolato, M.; Antunes, P.; Bejhed, R. S.; Zardán Gómez de la Torre, T.; Østerberg, F. W.; Strömberg, M.; Nilsson, M.; Strømme, M.; Svedlindh, P.; Hansen, M. F.; Vavassori, P. Novel Readout Method for Molecular Diagnostic Assays Based on Optical Measurements of Magnetic Nanobead Dynamics. Anal. Chem. 2015, 87, $1622-1629$.

(40) Zhang, P. H.; He, Z. M.; Wang, C.; Chen, J. N.; Zhao, J. J.; Zhu, X. N.; Li, C. Z.; Min, Q. H.; Zhu, J. J. In Situ Amplification of 
Intracellular MicroRNA with MNAzyme Nanodevices for Multiplexed Imaging, Logic Operation, and Controlled Drug Release. ACS Nano 2015, 9, 789-798.

(41) Peng, H. Y.; Li, X. F.; Zhang, H. Q.; Le, X. C. A microRNAinitiated DNAzyme motor operating in living cells. Nat. Commun. 2017, 8, 14378.

(42) Fock, J.; Jonasson, C.; Johansson, C.; Hansen, M. F. Characterization of fine particles using optomagnetic measurements. Phys. Chem. Chem. Phys. 2017, 19, 8802-8814.

(43) Tian, B.; Bejhed, R. S.; Svedlindh, P.; Strömberg, M. Blu-ray optomagnetic measurement based competitive immunoassay for Salmonella detection. Biosens. Bioelectron. 2016, 77, 32-39.

(44) Tian, B.; Ma, J.; Zardán Gómez de la Torre, T.; Bálint, Á.; Donolato, M.; Hansen, M. F.; Svedlindh, P.; Strömberg, M. Rapid Newcastle Disease Virus Detection Based on Loop-Mediated Isothermal Amplification and Optomagnetic Readout. ACS Sensors 2016, 1, 1228-1234.

(45) Tian, B.; Ma, J.; Qiu, Z.; Zardán Gómez de la Torre, T.; Donolato, M.; Hansen, M. F.; Svedlindh, P.; Strömberg, M. Optomagnetic Detection of MicroRNA Based on Duplex-Specific Nuclease-Assisted Target Recycling and Multilayer Core-Satellite Magnetic Superstructures. ACS Nano 2017, 11, 1798-1806.

(46) Mokany, E.; Bone, S. M.; Young, P. E.; Doan, T. B.; Todd, A. V. MNAzymes, a Versatile New Class of Nucleic Acid Enzymes That Can Function as Biosensors and Molecular Switches. J. Am. Chem. Soc. 2010, 132, 1051-1059.

(47) Cox, A. J.; Bengtson, H. N.; Rohde, K. H.; Kolpashchikov, D. M. DNA nanotechnology for nucleic acid analysis: multifunctional molecular DNA machine for RNA detection. Chem. Commun. 2016, 52, 14318-14321.

(48) Zhou, W. H.; Chen, Q. Y.; Huang, P. J. J.; Ding, J. S.; Liu, J. W. DNAzyme Hybridization, Cleavage, Degradation, and Sensing in Undiluted Human Blood Serum. Anal. Chem. 2015, 87, 4001-4007.

(49) Santoro, S. W.; Joyce, G. F. Mechanism and utility of an RNAcleaving DNA enzyme. Biochemistry 1998, 37, 13330-13342.

(50) Bakshi, S. F.; Guz, N.; Zakharchenko, A.; Deng, H.; Tumanov, A. V.; Woodworth, C. D.; Minko, S.; Kolpashchikov, D. M.; Katz, E. Nanoreactors based on DNAzyme-functionalized magnetic nanoparticles activated by magnetic field. Nanoscale 2018, 10, 1356-1365.

(51) Weber, J. A.; Baxter, D. H.; Zhang, S. L.; Huang, D. Y.; Huang, K. H.; Lee, M. J.; Galas, D. J.; Wang, K. The MicroRNA Spectrum in 12 Body Fluids. Clin. Chem. 2010, 56, 1733-1741.

(52) Williams, Z.; Ben-Dov, I. Z.; Elias, R.; Mihailovic, A.; Brown, M.; Rosenwaks, Z.; Tuschl, T. Comprehensive profiling of circulating microRNA via small RNA sequencing of cDNA libraries reveals biomarker potential and limitations. Proc. Natl. Acad. Sci. U. S. A. 2013, 110, 4255-4260.

(53) Lesnik, E. A.; Freier, S. M. Relative Thermodynamic Stability of DNA, Rna, and DNA-Rna Hybrid Duplexes - Relationship with Base Composition and Structure. Biochemistry 1995, 34, 10807-10815. 